\title{
A Scanning Microwave Radar and Radiometer
}

\section{Skou, Niels}

Published in:

Combined Optical-Microwave Earth and Atmosphere Sensing, 1995. Conference Proceedings., Second Topical Symposium on

Link to article, DOI:

10.1109/COMEAS.1995.472318

Publication date:

1995

Document Version

Publisher's PDF, also known as Version of record

Link back to DTU Orbit

Citation (APA):

Skou, N. (1995). A Scanning Microwave Radar and Radiometer. In Combined Optical-Microwave Earth and Atmosphere Sensing, 1995. Conference Proceedings., Second Topical Symposium on (pp. 215-216). IEEE. https://doi.org/10.1109/COMEAS.1995.472318

\section{General rights}

Copyright and moral rights for the publications made accessible in the public portal are retained by the authors and/or other copyright owners and it is a condition of accessing publications that users recognise and abide by the legal requirements associated with these rights.

- Users may download and print one copy of any publication from the public portal for the purpose of private study or research.

- You may not further distribute the material or use it for any profit-making activity or commercial gain

- You may freely distribute the URL identifying the publication in the public portal

If you believe that this document breaches copyright please contact us providing details, and we will remove access to the work immediately and investigate your claim. 


\title{
A SCANNING MICROWAVE RADAR \& RADIOMETER
}

\author{
Niels Skou \\ Danish Center for Remote Sensing \\ Electromagnetics Institute, B 348 \\ Technical University of Denmark \\ DK 2800 Lyngby, Denmark \\ Phone: +4542881444 \\ Fax: +45 45931634 \\ e-mail: ns@emi.dtu.dk
}

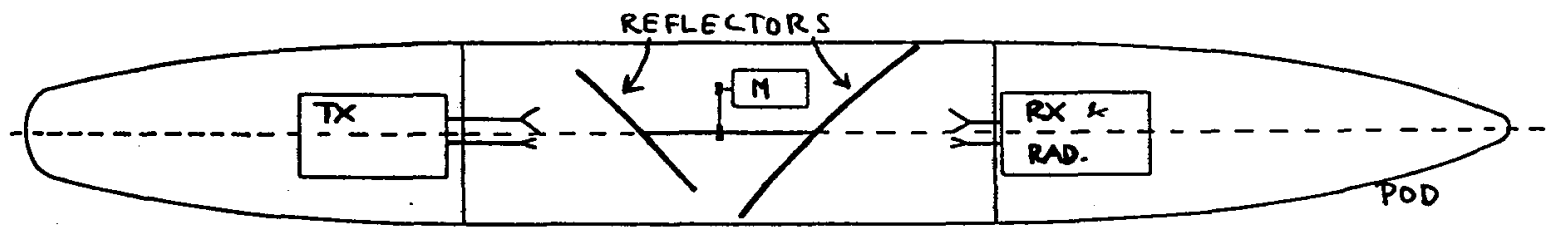

Figure 1: The Instrument in the Pod

\section{System Overview}

The Scanning Microwave Radar \& Radiometer (SMRR) is a line scanner featuring a combined radar and radiometer system operating around 35 and $94 \mathrm{GHz}$. The key word is synergism - in this case trying to use both active and passive measurements to obtain information not otherwise available using either one of these alone. This has been done before using separate radars and radiometers, but always hampered by lack of simultaneousness and lack of identical footprints.

The layout of the SMRR is shown in Figure 1. The 2 offset antenna parabolas scan in syncronism, the receiver antenna has the higest gain in order to ensure that footprints are identical for the radar and the radiometer. The instrument will be flown in a pod under a Gulfstream G3 normally cruising with $240 \mathrm{~m} / \mathrm{sec}$ at $12500 \mathrm{~m}(41000 \mathrm{ft})$, and will thus be able to sense clouds and precipitation from above. In the following it will be assumed that the clouds to be sensed are $10000 \mathrm{~m}$ below the aircraft.

\section{The 35 GHz Radiometer}

The pod limits the antenna aperture to $45 \mathrm{~cm}$ which corresponds to a beamwidth of $0.023\left(1.3^{\circ}\right)$, and hence a footprint at $10 \mathrm{~km}$ distance of $230 \mathrm{~m}$ (288 $\mathrm{m}$ at the surface of the Earth). The receiver noise figure is $5 \mathrm{~dB}$ and the pre-detection bandwidth is $500 \mathrm{MHz}$. We require contiguous coverage of the clouds and a $30 \%$ footprint overlap to ensure proper sampling. 20 footprints across track are imaged resulting in a swath of $4600 \mathrm{~m}$. Using a sinusoidal across track scan pattern and the nominal flight conditions the minimum footprint dwell time is found to be 21.3 msec. Again, requiring $30 \%$ overlap for proper sampling this implies a $15 \mathrm{msec}$ sampling interval and integration time in the radiometer. For a total power radiometer we thus calculate a sensitivity $\Delta \mathrm{T}=0.34 \mathrm{~K}$

\section{The 35 GHz Radar}

The transmitter is based on a $46 \mathrm{~kW}$ magnetron having a pulse width of $125 \mathrm{nsec}$ and a duty cycle of $0.1 \%$. The corresponding bandwidth is $8 \mathrm{MHz}$, the range resolution $18.75 \mathrm{~m}$, and the maximum PRF is $8 \mathrm{kHz}$ leading to an unambiguous range of $18.75 \mathrm{~km}$. The simple, brute force transmitter technique is chosen due to the unfavourable sensing situation where very week signals from the clouds must be measured with little time difference to the ground return typically $60 \mathrm{~dB}$ stronger. Pulse compression techniques with time sidelobes way below $-60 \mathrm{~dB}$ is very difficult if not impossible.

The receiver noise figure of $5 \mathrm{~dB}$ and the bandwidth of $8 \mathrm{MHz}$ results in a receiver noise level of $-100 \mathrm{dBm}$. The transmitter power of 46 $\mathrm{kW}$ equals $77 \mathrm{dBm}$ and the system sensitivity is $177 \mathrm{~dB}$ (for $\mathrm{S} / \mathrm{N}=1$ ). Assuming at first for simplicity that equal sized antennas are used for transmission and reception $(45 \mathrm{~cm}$ aperture corresponds to some $42 \mathrm{~dB}$ gain at $35 \mathrm{GHz}$ ) the radar equation predicts a round trip loss of $\mathrm{P}_{\mathrm{R}} / \mathrm{P}_{\mathrm{T}}=6.4 \times 10^{-10} \times \sigma^{\mathrm{V}}, \sigma^{\mathrm{V}}$ being the volume backscattering coefficient. For normal, nonprecipitating clouds consisting of water droplets $\left(1 \mathrm{~g} / \mathrm{m}^{3}\right) \sigma^{\mathrm{V}}=2.4 \times 10^{-9}$ is a typical value, see (1) and (2). Inserting this figure in the above 
expression for the round trip loss results in a value of $-178 \mathrm{~dB}$, and the single pulse signal to noise ratio will be close to 1 . For a typical ice cloud the situation is quite different as $\sigma \mathrm{V}=1.0 \mathrm{x}$ $10^{-4}$ is a realistic value, resulting in a round trip loss of $-132 \mathrm{~dB}$, hence a single pulse signal to noise ratio of $+45 \mathrm{~dB}$.

Signal to noise ratio can be improved by integration of pulses. The dwell time per footprint is $21.3 \mathrm{msec}$ and with a PRF of $8 \mathrm{kHz}$ we find a potential for integrating 170 pulses. Incoherent integration of 170 pulses will give a gain of $16 \mathrm{~dB}$ for a non-fluctuating target. However, this is hardly the case for the present distributed target, and the $16 \mathrm{~dB}$ can be regarded as an upper limit. If we consider the Swerling cases 1 and 2 (many small scatterers, none dominating) we get integration gains ranging from the $16 \mathrm{~dB}$ (Sw. 2: de-correlation from pulse to pulse) to $5 \mathrm{~dB}$ (Sw. 2: no de-correlation over integration period). So, de-correlation is an important property. If we move $1 / 2$ antenna aperture a distributed target de-correlates. Since we move at $240 \mathrm{~m} / \mathrm{sec}$ we get at least 23 independent samples per footprint. Incoherent integration of 23 independent pulses will give an integration gain of $11 \mathrm{~dB}$. Hence, we can expect an integration gain of 11 to $16 \mathrm{~dB}$ and for the typical water cloud the resulting signal to noise ratio will be 10 to $15 \mathrm{~dB}$.

In order to obtain the same footprint for the radiometer and the radar measurements it is necessary that the radar antenna beam is wider than the receiver antenna beam. In principle it should be constant over the significant portion of the receiver beam. The price to pay is of course loss in sensitivity according to the loss in transmit antenna gain. Since we do not have superfluous sensitivity at hand a compromise must be made. The SMRR is made with 2 equal sized reflectors and by changing feed horns on the transmitter for potential underillumination of the reflector, different options to be tried in real life is readily at hand.

\section{$94 \mathrm{GHz}$ Channel}

The noise figure of the receiver is $7 \mathrm{~dB}$, and in the radiometer mode the bandwidth is $1 \mathrm{GHz}$. The $94 \mathrm{GHz}$ channel will underilluminate the reflectors to obtain a footprint identical to that of the $35 \mathrm{GHz}$ channel.

The radiometer sensitivity is slightly degraded to $0.38 \mathrm{~K}$

The transmitter is based on a $2.5 \mathrm{~kW}$ magnetron having a pulse width of 50 nsec. Compared with the $35 \mathrm{GHz}$ radar we have a change in the round trip loss of $-13 \mathrm{~dB}$ on the peak power, $-4 \mathrm{~dB}$ on the bandwidth, $-4 \mathrm{~dB}$ on the pulse length, and -3 $\mathrm{dB}$ on the noise figure. However, we gain on the frequency. The radar equation changes with the wavelength to the second power while $\sigma^{\mathrm{V}}$ changes with frequency to the fourth power, and the result is a gain of $9 \mathrm{~dB}$. Hence, the total round trip loss is degraded with - $15 \mathrm{~dB}$, and the signal to noise ratio after proper integration will be below $0 \mathrm{~dB}$ for typical water clouds. While the 94 $\mathrm{GHz}$ channel is not very useful for water clouds, ice clouds will be well imaged.

\section{Sensing of the Earth's Surface}

The instrument will also be useful for sensing of the surface of the Earth. The radar equation predicts a round trip loss of $\mathrm{P}_{\mathrm{R}} / \mathrm{P}_{\mathrm{T}}=2.2 \times 10^{-11} \mathrm{x}$ $\sigma_{0}$. A typical value for sigma naught is $-10 \mathrm{~dB}$ for land surfaces, and the resulting round trip loss is $-117 \mathrm{~dB}$ leading to ample sensitivity.

A special aspect of the high return of the ground compared with the water clouds (typically $60 \mathrm{~dB}$ difference) is the possibility of interference. Problems with pulse compression have already been discussed. Antenna sidelobes pointing towards the ground is a potential problem, but not in a nadir looking system. At the swath edges the slant range distance to the ground is $330 \mathrm{~m}$ larger than the nadir distance to the ground. Hence the large nadir return in general precludes the measurement of clouds below $330 \mathrm{~m}$.

\section{Sensing of Rain}

The instrument will also be very well suited for detailled studies of rain. The sensitivity is ample due to the reflectivity factor being orders of magnitude larger for even moderate rain than for water clouds. The high frequency will suffer from loss passing through the rain, but due to the nadir geometry and the associated short path length this never becomes a problem.

\section{Conclusions}

An airborne, imaging cloud sensor has been described. It combines a radar and a radiometer to ensure exact simultaneousness and equal footprints for active and passive measurements. Other cloud radars are around, often featuring a doppler mode, but normally ground based. This radar is an imager providing detailled spatial information.

\section{References}

(1) Ulaby, F. T., Moore, R. K., and Fung, A. K: "Microwave Remote Sensing, Vol.1", Artech House

(2) Sauvageot, H. and Omar, J.:

"Radar Reflectivity of Cumulus Clouds", Journal of Atmospheric and Oceanic Technology. June 1987 